\title{
Research of Development Trend of College Physical Education under the concept of lifelong sports
}

\author{
Shan CHEN \\ Chengdu University of Information Technology \\ Chengdu,Sichuan,610225 China
}

\begin{abstract}
Lifetime Sports is the inevitable trend of development of physical education, as an important part of sports, physical education and community colleges is also bound to be affected by the concept of lifelong physical challenges and impact, how to implement the concept of lifelong physical education in college sports and how to raise awareness of college students to become lifelong sports are the important issue of Physical Education workers and they need attention. Based on the need to implement lifelong physical elaborated on, from stressed education transformation Sports theoretical knowledge of PE teaching mode Trends in College Physical Education were studied and discussed under the concept of lifelong sports.
\end{abstract}

Keywords- Lifelong sports, college sports teaching, trends

\section{INTRODUCTION}

Lifelong sports in college sports are one of the words used most frequently. Back in the 1980s, China had a large number of scholars on the relationship between school sports and lifelong physical exploration, china has proposed school sports, especially sports curriculum reform must focus on the goal of lifelong physical, some studies put the lifelong sport as a basic school of Physical Education. Lifetime Sports has become the slogan from the past and it is an important concept of physical education, it became the basic guiding principle to build and design college physical education teaching program, and it must be based on the target.

\section{A CONCEPT OF LIFELONG SPORT EXISTS IN THE SENSE} OF PHYSICAL EDUCATION IN COLLEGES AND UNIVERSITIES.

\section{A. The concept of lifelong sports}

After the proposed Lifelong Education, the world will soon become an important basis is for the development of education policy and related fields, and in the field of sports it also had a profound impact. Since then, the world sports community has been using the term lifelong sports, lifelong education is actually a special meaning expressed in the sports field. Obviously, lifelong physical expression is the specific content of lifelong education in the field of sports, namely lifelong physical education, but the term itself is education sports connotation, so we call it the Lifetime Sports. It never refers to the connotation of lifelong exercise like our general understanding, but refers to a person from birth to death accepted uninterrupted and continuous physical education system, it should be emphasized that every member of society at any time, and any spaces are required to accept all forms of physical education, to adapt to the development of society. General lifelong engage in sports are mainly as follows: First, whether they have one or more physical exercise skills, second, whether theoretical grasp of basic knowledge of sports, third, whether they have physical exercise, entertainment and the ability to appreciate; Finally, the ability to exercise self-judgment effect.

\section{B. Meaning of lifelong sports philosophy in college physical education}

Lifetime sports concept in the College Physical Education is a way to educate people and integrate the concept of sustainable development, the concept is built on the basis of people-oriented, not only students can get a better physical education in school, but also they can effectively improve the students' interest in participating in sports, and it makes students master a unique athletic talent, so students develop good exercise habits laying on the foundation to promote student social life, and in the future students still have a certain sport exercise behavior and interests. Therefore, the concept of lifelong sports in Physical Education will make the role of educating people of Physical Education play better results.

Shortage exists in Physical Education under two lifelong sports concepts.

In recent years, the reform of college sports is in terms of teaching materials, teaching methods and teaching methods, although some progress has been made, but on the whole in terms of the current reform of college sports it is still relatively backward. The problem lies in the following aspects: first, the students' lifelong sports is consciousness, lifelong power sports reflects people's internal factors, those who are determined to become the vital Ganwudao "My body sports keep peace, music almost my heart," the significance and the physical fitness are as a success on the basis of physical exercise but most students are not interested in even disgust, they fear sports, learn physical education just to pass the exam, they lack of a rational understanding of lifelong sports. Second, the students' lifelong physical exercise capacity is weak, since long time ago, school physical educational student focus on physical aspects of education, and ignore its ability to develop sports consciousness, there is a certain lack of student sports consciousness, they have poor ability to self physical exercise, and do not consciously actively participate in physical exercise. Third, teaching methods and teaching are form a single organization over the years, physical education teachers have been in strict accordance with explanation and 
demonstration, practice, and correct the error prevention than to consolidate and improve the model of a single Physical Education teaching methods, students' lack of initiative and vitality physical education makes teaching seem mechanical, dull, not arouse students' interest in recent years, with the deepening of the reform of college sports there are some new teaching methods. However, due to the constraints course structure, teaching system, teachers and other aspects of the application of new teaching methods also face narrow, dull factors and it does not solve the PE class exercises which are not enthusiastic about the situation radically higher, the potential for educating people does not play physical education.

\section{NECESSITY IN ESTABLISHING LIFELONG PHYSICAL EXERCISE IN COLLEGE PHYSICAL EDUCATION}

From college physical education setting, the current exception of a few schools are with better conditions, the vast majority of schools operate only in first and second grade gym class, and generally it is once or twice a week, but to get the full development of the body, to enhance the physical fitness of purpose, we must conduct a comprehensive physical exercise often, these few minutes alone Physical exercise are clearly not enough. From college students in the exercise of clear conditions currently, in addition to a small number of specialty sports fans, we should to adhere to the annual exercise. Especially after entering high school physical education ending, student constraints from physical education curriculum and performance, the number of physical activity significantly is less than one year before. Second, there are quite a few people feel physically better than one, when sophomore is strong. From our social situation, according to the data which indicates the investigation of Chinese universities, research institutes engaged in mental officers found more than 90 percent of sub-health state occurs, more than $60 \%$ of people suffering from various other diseases, but these diseases all can be are controlled through physical exercise. The above description of the social sport is not optimistic. Therefore it is imperative to establish lifelong physical education thought.

\section{ANALYZES THE STATUS OF COLLEGE SPORTS}

\section{A. The problem of unclear Goal of Colleges Physical Education}

Currently, the college physical education course in our country has the problem that target is not clear, most colleges and universities will enhance students' physical fitness as the only target, thus ignoring the concept of lifelong physical training of students, resulting in that lifelong consciousness of college students is weak, a lot of college students generally do not develop the habit of lifelong physical exercise, especially after they move towards social, they have less physical activity, physical exercise leads to fragmentation of social needs and college Physical Education.

\section{B. College physical education activities hard to match social needs}

At present, the country sets up college sports programs, there are the teaching content and social needs mismatch problem. First, from the theory of teaching physical education curriculum, the university has not yet formed a theory of knowledge and the development of modern society sports. Secondly, from the practice of college physical education teaching, the competitive sports program is the main teaching content, and it lacks of exercise and sport skills to master teaching methodologies of self-protection. On the perspective of teaching content and teaching in primary schools from teaching sports to college sports, its contents are basically the same, college physical education is difficult to effectively enhance the formation and in-depth teaching on the basis of school sports. From college physical education curriculum arrangement point of view, physical education curriculum in our universities special course of study time is shorter, some students are just after the interest generated by the project for teaching, because teaching time has come to have to re-learn another door Physical Education courses, resulting in poor physical ability of students, low quality sports, weak sports consciousness and other issues.

\section{PHYSICAL EDUCATION COLLEGE TRENDS}

\section{A. Arrange college physical education class, and adjust the time of Physical Education}

Accordance with the requirements of lifelong sports concept, and now college physical education class has been unable to meet the needs of sports teaching reform, it is only once or twice a week course, students have to master all of the teaching content, expertly complete sports, it is invisible an increase of a lot of pressure to students, they will prone to negative emotions, learn to lose confidence in sports, so the teaching reform of college sports should be adjusted according to the actual situation of sports instructional time, increasing physical education courses not only helps to make progress on student learning, but also for the need for lifelong sports concept.

\section{B. Full play the students 'initiative, pay attention to the development of students' personality}

Each student has their own characteristics, their physical condition and capabilities are not the same, so the knowledge and skills of college sports are uneven ability to comprehend, we can see that college sports teaching reform must take the "people-oriented" person the ideology as a prerequisite, under different circumstances, different students, teaching methods have changed, the students are as the main classroom, we should enhance their awareness of the initiative, and under the guidance of teachers, starting from their own actual situation, we develop a personalized approach to learning, and strive to enhance their capabilities.

\section{Imparting knowledge and skills is as a pilot}

School physical education should first reflect the knowledge and skills to impart teaching tasks conferred as teaching, we organic combine teaching sports knowledge, 
technology and skills and scientific principles of physical exercise to effectively achieve enhanced physical fitness of students and lifelong benefit sports view. Therefore, in physical education we must first pay attention to sports knowledge, technology and skills, providing students with scientific knowledge and methods to exercise the body.

\section{Direction of Lifelong Physical}

Lifelong Physical Education is the long-term goal of the school physical educational system, school physical education is the core guiding ideology. Clearly this goal, "to impart knowledge and skills as a pilot," the guiding ideology of school physical education is described earlier, it is not limited to one semester or one academic year to pursue shortterm benefit, it is not only in schools but also relate to the effectiveness of the learning phase targets, but from the consciousness of students engaged in lifelong physical activity, habits and the ability are to view, similar to properly handle the relationship between different types of sports programs and physical education curriculum to teach sports related knowledge and skills, we enhance physical fitness, improve physical ability and personality development and so on. WE should correctly understand and handle the relationship between recent sports teaching effectiveness, efficiency and long-term benefits of the interim are to seek lifelong sports around this long-term goal, and constantly develop the students' physical ability, enhance the body, lay the foundation for lifelong physical, thus students will last a lifetime.

\section{E. Changes in classroom physical teaching}

To mobilize students' interest in sports is the key to lifelong sports consciousness in college physical education, so in college teaching in physical education content, we try to fit the physical and psychological characteristics of students with the game of sports items and athletic sports items to enhance students' Physical education and sport participation. As the college has a relatively mature thinking and certain sports foundation, the traditional teaching model is difficult to meet the physical requirements of university classroom, and to build on the university classroom must be boring, single teaching method will instill make changes based sports teaching mode changed to AC-based physical education teaching.

\section{F. $\quad$ Teacher tutoring learning}

For E classes, due to limitations of syllabus, facilities, special sports pervasiveness and ease of movement skills by objective conditions, some of the items or content is not completed to teach physical education, these projects are often the ones loved and needed precisely by some students. PE teachers use student counseling extracurricular exercise time special technology to meet the aspirations of students engaged in sports activities, and one of the important means is to develop students' skills, and help lower class students to consciously exercise.

\section{G. Courses offered for special sports}

Make full use of the college faculty, facilities and ample spare time and other favorable conditions to establish courses for special sports, some of the special campaign launched at the beginning, intermediate and advanced training courses and seminars classes of theoretical knowledge, we absorb the students of interest and a certain level to train so that they get to learn and improve on the original basis, so as to improve the skills of continuous development.

\section{H. Develop special club founder}

In regions where economy is flourished, students' physical education has changed club-style teaching methods, students according to their own needs, to free choice of some sport to learn and exercise activities. As the economy continues to develop, the condition of most of the sports facilities and other colleges and universities in the region will be improved, and they gradually have the condition to achieve the establishment of the club. Special sports can improve the ability and enhance the achievement of lifelong physical and make lifelong.

Beneficiary has a very important role.

\section{CONCLUSION}

Students grow and develop during the college time, and they form personality this time, college time is also a critical period of lifetime sports consciousness and formation of all ability. Organic integration of college sports and lifelong physical sports will directly determine how the college students sustain and have effective lifelong physical exercise ability and habit of lifelong sports out of school. Physical Education of College Sports disjointed with society to some extent, they have too much emphasis on technical education and culture to the neglect of sports knowledge dissemination, and the dominant position of students being watered down. Therefore, teachers in Higher Education should strengthen the cultivation of students' lifelong sports consciousness and life-long physical exercise capacity.

\section{REFERENCES}

[1] Lixin. Lifelong Sports Concept College Physical Education Reform under the guidance of $[\mathrm{J}]$. Contemporary sports science and technology, 2013,21:120 +122.

[2] Liu Yarong, Liai Qin. Teaching Reform on College Sports under the concept of lifelong sports[J]. Chinese science and innovation Tribune, 2007,25:76.

[3] Huang Guoqin. Lifetime Sports and Physical Education in Colleges[J]. Yangzhou College of Education,2008,01:53-56.

[4] Guo Xiaoguang Sports Teaching Reform ideas lifelong physical education [4]Chifenggang. College in the analysis[J]. (Natural Science Edition),2012,08:134-135.

[5] Shao Yi. Teaching Reform under the Lifelong Sports College Sports Thought [J]. Chinese adult education,2009,03:115-116.

[6] Peng Lingqun, Wang Qiang, physical education teaching philosophy of lifelong sports culture [J]. Occupation temporal,2009,06:97-98.

[7] Wangxilaing, Liu Chunmei. Positive impact on college sports teaching reform ideas for establishing lifelong sports [J]. Weekly,2009,38:121-122 exam. 